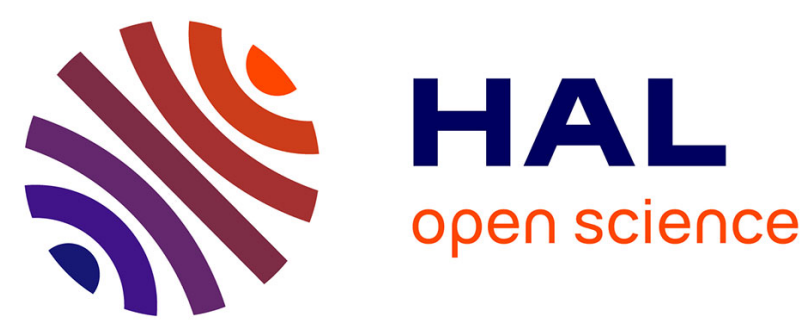

\title{
Increase in insulin sensitivity by the association of chicoric acid and chlorogenic acid contained in a natural chicoric acid extract (NCRAE) of chicory ( Cichorium intybus L.) for an antidiabetic effect
}

Karine Ferrare, Luc Bidel, Abdulmomem Awwad, Patrick Poucheret, Guillaume Cazals, Françoise Lazennec, Jacqueline Azay-Milhau, Michel Tournier, Anne-Dominique Lajoix, Didier Tousch

\section{- To cite this version:}

Karine Ferrare, Luc Bidel, Abdulmomem Awwad, Patrick Poucheret, Guillaume Cazals, et al.. Increase in insulin sensitivity by the association of chicoric acid and chlorogenic acid contained in a natural chicoric acid extract (NCRAE) of chicory ( Cichorium intybus L.) for an antidiabetic effect. Journal of Ethnopharmacology, 2018, 215, pp.241 - 248. 10.1016/j.jep.2017.12.035 . hal-01880711

\section{HAL Id: hal-01880711 \\ https://hal.umontpellier.fr/hal-01880711}

Submitted on 26 May 2020

HAL is a multi-disciplinary open access archive for the deposit and dissemination of scientific research documents, whether they are published or not. The documents may come from teaching and research institutions in France or abroad, or from public or private research centers.
L'archive ouverte pluridisciplinaire HAL, est destinée au dépôt et à la diffusion de documents scientifiques de niveau recherche, publiés ou non, émanant des établissements d'enseignement et de recherche français ou étrangers, des laboratoires publics ou privés.

\section{(ㅇ)(1) $\$$}

Distributed under a Creative Commons Attribution - NonCommercial - NoDerivatives $\mid 4.0$ 


\section{Author's Accepted Manuscript}

Increase in insulin sensitivity by the association of chicoric acid and chlorogenic acid contained in a natural chicoric acid extract (NCRAE) of chicory (Cichorium intybus L.) for an antidiabetic effect

Karine Ferrare, Luc. P.R. Bidel, Abdulmomem Awwad, Patrick Poucheret, Guillaume Cazals, Françoise Lazennec, Jacqueline Azay-Milhau,

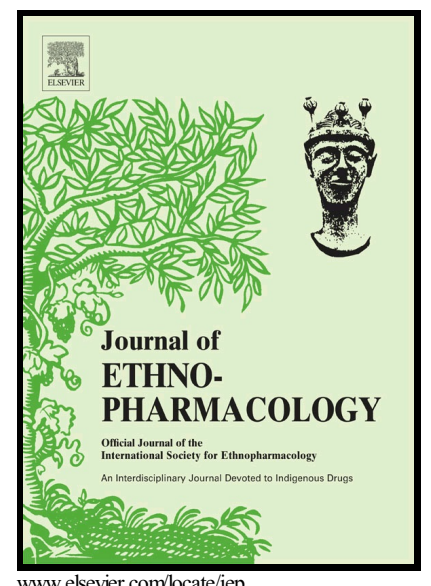
Michel Tournier, Anne-Dominique Lajoix, Didier Tousch

PII: S0378-8741(17)33242-7

DOI: $\quad$ https://doi.org/10.1016/j.jep.2017.12.035

Reference: JEP11166

To appear in: Journal of Ethnopharmacology

Received date: 29 August 2017

Revised date: 18 December 2017

Accepted date: 24 December 2017

Cite this article as: Karine Ferrare, Luc. P.R. Bidel, Abdulmomem Awwad, Patrick Poucheret, Guillaume Cazals, Françoise Lazennec, Jacqueline AzayMilhau, Michel Tournier, Anne-Dominique Lajoix and Didier Tousch, Increase in insulin sensitivity by the association of chicoric acid and chlorogenic acid contained in a natural chicoric acid extract (NCRAE) of chicory (Cichorium intybus L.) for an antidiabetic effect, Journal of Ethnopharmacology, https://doi.org/10.1016/j.jep.2017.12.035

This is a PDF file of an unedited manuscript that has been accepted for publication. As a service to our customers we are providing this early version of the manuscript. The manuscript will undergo copyediting, typesetting, and review of the resulting galley proof before it is published in its final citable form. Please note that during the production process errors may be discovered which could affect the content, and all legal disclaimers that apply to the journal pertain. 
Increase in insulin sensitivity by the association of chicoric acid and chlorogenic acid contained in a natural chicoric acid extract (NCRAE) of chicory (Cichorium intybus L.) $^{2}$ for an antidiabetic effect

Karine Ferrare $^{\mathrm{a} 1}$, Luc. P. R. Bidel ${ }^{\mathrm{b} 1}$, Abdulmomem Awwad ${ }^{\mathrm{a}}$, Patrick Poucheret ${ }^{\mathrm{a}}$, Guillaume Cazals $^{\mathrm{c}}$, Françoise Lazennec ${ }^{\mathrm{a}}$, Jacqueline Azay-Milhau ${ }^{\mathrm{d}}$, Michel Tournier ${ }^{\mathrm{d}}$, Anne-Dominique Lajoix $^{\mathrm{d}}$, Didier Tousch ${ }^{\mathrm{a}}$

${ }^{a}$ University Montpellier, UMR 95 Qualisud, CIRAD, SupAgro Montpellier, University of Avignon, University of the Reunion, 15 Avenue Charles Flahault, BP 14491, 34093

Montpellier Cedex 5, France

${ }^{\mathrm{b}}$ INRA, UMR AGAP, CIRAD, SupAgro, 2 Place Pierre Viala, 34060 Montpellier, France

${ }^{c}$ University Montpellier, IBMM UMR5247, CNRS, ENSCM, Place Eugène Bataillon, 34095

Montpellier Cedex 5, France

${ }^{\mathrm{d}}$ University Montpellier, EA 7288, Biocommunication in Cardio-Metabolism, 15 Avenue

Charles Flahault, BP14491, 34093 Montpellier Cedex 5, France

*Corresponding author: Tel.: +33 4117595 60. didier.tousch@umontpellier.fr

\section{ABSTRACT}

Ethnopharmacological relevance

Chicory (Cichorium intybus L.) is an indigenous vegetable widely cultivated in Europe, America and Asia. In ancient times, the leaves, flowers, seeds, and roots have been used as a wealth of health benefits including its tonic effects, the ability to ease digestive problems and to detoxify liver. In Indian traditional therapy, chicory was known to possess antidiabetic effect. In the traditional medicine of Bulgaria and Italy, chicory was used as hypoglycemic decoctions.

Aims of the studies

We wanted to obtain the complete chemical composition of the natural chicoric acid extract (NCRAE), a chicory root extract rich in chicoric acid, which previously showed its glucose tolerance effect in normal rats. To investigate if the whole NCRAE is required to be effective, we performed a comparative in vivo experiment on STZ diabetic rats treated either with NCRAE or a mixture composed of the two major compounds of NCRAE.

\section{Materials and Methods}

\footnotetext{
${ }^{1}$ K. Ferrare and L.P.R. Bidel contributed equally to this study. 
LC-MS method has been used to analyze the exhaustive composition of NCRAE: we have ACCEPTED MANUSCRIPT

determined that chicoric acid and chlorogenic acid represented $83.8 \%$ of NCRAE. So, we have prepared a solution mixture of chicoric acid and chlorogenic acid named SCCAM, in order to compare in vivo the antidiabetic effects of this last and NCRAE in streptozotocin diabetic rats. In vitro experiments were performed on L6 cell line both for glucose uptake and for the protective effect against $\mathrm{H}_{2} \mathrm{O}_{2}$ oxidative stress. Also, we have evaluated DPPH and ORAC (Oxygen Radical Absorbance Capacity) antioxidative capacities of the two compositions.

\section{Results}

The LC-MS analysis confirmed the high abundance of chicoric acid (64.2\%) in NCRAE and a second part of NCRAE is composed of caffeoylquinic acids (CQAs) at 19.6\% with among them the chlorogenic acid. This result has permitted us to prepare a mixture of synthetic Lchicoric acid (70\%) and synthetic chlorogenic acid (30\%): the solution is designated SCCAM. Our results showed that both NCRAE and SCCAM are able to improve a glucose tolerance in STZ diabetic rats after a subchronic administration of seven days. Alone NCRAE allows to significantly decrease the basal hyperglycemia after six days of treatment. To explain these difference of effects between NCRAE and SCCAM, we have compared their in vitro effects on the L6 muscle cell line both for the insulin sensitizing effect and for their protective action in pretreatment against $\mathrm{H}_{2} \mathrm{O}_{2}$. We have also compared their antioxidant capacities. In conclusion, we demonstrated that NCRAE, a natural extract of chicory (Cichorium intybus) rich in CRA and CQAs improves glucose tolerance and reduces the basal hyperglycemia in STZ diabetic rats. 


\section{Cichorium}
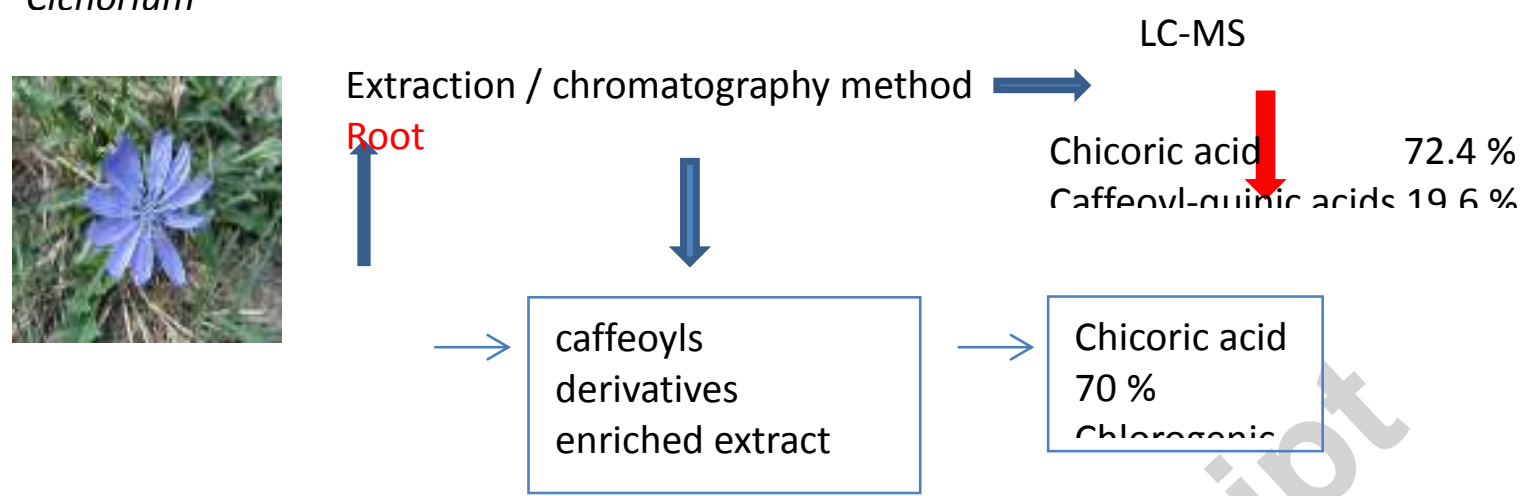

\section{In vivo experiments on} strentomatorin

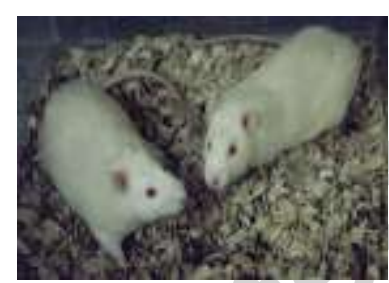

NCRAE contained a mixture of CRA, CGA and others raffenul derivatives that ronfer thic antidiahotir

Keywords

Cichorium intybus L. root extract; LC-MS analysis; Chicoric acid and chlorogenic acid; Streptozotocin diabetic rats; Antidiabetic effect; L6 cells oxidative stress assay; L6 cell glucose uptake 


\section{ACCEPTED MANUSCRIPT}

\section{Introduction}

Type 2 diabetes (T2D) is amongst the most common metabolic diseases worldwide. It affected about 350 million people in 2011 and this number will achieve 550 million in 2030 (Whiting et al., 2011). To treat this illness, oral hypoglycemic agents including insulin secretagogues such as sulfonylureas, insulin sensitizing agents such as metformin and intestinal alpha glucosidase inhibitors such as acarbose are currently used. To restore a normal glycemia, alternative therapeutics consisting to use natural compounds extracted from plants are in studies. In traditional medicine, the chicory (Cichorium intybus L.) was widely used to treat diabetes in India and Pakistan (Street et al., 2013). In their review of beneficial plants used in the popular traditional medicine of Italy and Bulgaria, Leporatti and Ivancheva (2003) have reported the traditional use of Cichorium intybus L. decoctions for their hypoglycemic property. The antidiabetic effect of an alcoholic chicory extract in streptozotocin-induced diabetic rats have been published by Pushparaj et al. (2007) and more recently by Ghamarian et al. (2012). Often, the anti-hyperglycemic properties of the polyphenolic compounds have been described (Cheng et al., 2003; Jung et al., 2006; Namura et al., 2003; Meng et al., 2013). In our previous works, we have demonstrated the anti-hyperglycemic properties of a chicory (Cichoryum intybus L.) root extract (natural chicoric acid extract; NCRAE) and a burdock (Arctium lappa L.) root (dried burdock root extract; DBRE) extract (Azay-Milhau et al., 2013; Tousch et al., 2014). These two Asteraceas extracts contain a lot of caffeoyl-derivatives. The chicory extract (NCRAE), rich in chicoric acid (dicaffeoyl tartaric acid) has a in vitro ability to increase glucose uptake in L6 muscular cell line (Tousch et al., 2008; Azay-Milhau et al., 2013). Moreover, in vivo experiments by an intraperitoneal glucose tolerance test on normal rats have brought evidence that NCRAE can improve glucose tolerance (Azay-Milhau et al., 2013). Caffeoyl derivatives, especially chicoric acid (CRA) and chlorogenic acid (CGA) are 
well documented in the literature for their antioxidant capacities (Fraisse et al., 2011; ACCEPTED MANUSCRIPT

Schlernitzauer et al., 2013; Niggeweg et al., 2004; Sato et al., 2011).

In the present work, we have investigated the antidiabetic capacity of NCRAE and endeavored understand the part played by the two most abundant caffeoyl compounds contained in this extract. For that, we performed initially the identification of all caffeoyl derivatives of the extract by LC-MS analysis. On the basis of the chemical characterization of NCRAE, we have prepared a composition named SCCAM (Synthetic Chicoric and Chlorogenic Acids Mixture) containing the two major compounds of NCRAE, in proportion of $70 \%$ of synthetic L-chicoric acid (CRA) and $30 \%$ of synthetic CGA. This ratio is very close of the NCRAE CRA/CQAs ratio. We performed an in vivo experiment on streptozotocin (STZ) diabetic rats treated by subchronic administrations of NCRAE or SCCAM. The results have shown that the two compositions are able to improve the glucose tolerance, but only NCRAE possesses the capacity to decrease the basal hyperglycemia in animals. To understand the differences of effect between NCRAE and SCCAM, we have compared their in vitro insulin sensitizing effects and their protective actions in pretreatment against $\mathrm{H}_{2} \mathrm{O}_{2}$ on the L6 muscle cell line and also their antioxidant capacities.

\section{Materials and methods}

\subsection{Biological material and drugs}

Chicory (Cichorium intybus L.) plants were collected in Montpellier (France) and identified by botanical biologists of Botanical Institute of Montpellier (Tela Botanica-Cichorium intybus L., identification number: 2121). Natural chicoric acid extract (NCRAE) of roots was obtained using the method previously described (Azay-Milhau et al., 2013) with modifications. Briefly, the powder of the part of plant was poured in a cellulose cartridge and placed in a EtOH-Water $(70: 30)$. The concentrated crude extract was passed through an LH20 (Sigma-Aldrich, Munich, Germany) column to recover the enriched extract 
polyphenols in a EtOH-Water $(40: 60)$. Commercial synthetic chicoric acid (CRA) and ACCEPTED MANUSCRIPT

chlorogenic acid (CGA) were purchased by Sigma-Aldrich. For L6 rat muscular cell culture,

Dulbecco's Modified Eagle's Medium (DMEM) and Fetal calf serum (FCS) was provided from Biochrom (Berlin, Germany). Cocktail medium, $2 \mathrm{mM} \mathrm{L-glutamine,100} \mathrm{U/mL} \mathrm{penicillin}$ and $100 \mu \mathrm{g} / \mathrm{mL}$ streptomycin, were purchased by Sigma-Aldrich. For diabetes induction, streptozotocin (STZ) was also provided by Sigma-Aldrich. For LC-MS analysis, acetonitrile (Carlo-Erba, France) and formic acid (Merck, Germany) were of HPLC-grade quality. Water was permuted using a reverse osmosis Milli-Q system (Millipore, France). Chlorogenic acid, $L$-chicoric acid, tartaric acid, quercetin-3-O-glucuronide, kaempferol-3-O-glucuronide were provided by Sigma-Aldrich.

\subsection{Chemical analysis of NCRAE by LC-MS}

In a first step, the extract was characterized using a Synapt G2-S high definition mass spectrometry system (Waters Corp., Milford, MA) equipped with electrospray ionization source, to characterize elemental composition of parent and fragment ions. Chromatographic separation was carried out at a flow rate of $0.4 \mathrm{~mL} \cdot \mathrm{min}^{-1}$ on Acquity H-Class ultrahigh performance liquid chromatography (UPLC) system (Waters Corp., Milford, MA), equipped with a Kinetex C18 100A column (100 x $2.1 \mathrm{~mm}, 2.6 \mu \mathrm{m}$ beads) from Phenomenex (France). The mobile phase consisted of permuted water (solvent A) and acetonitrile (solvent B), both phases acidified by $0.1 \%(\mathrm{v} / \mathrm{v})$ formic acid. Mass spectra were acquired in the positive and negative ionization mode with a capillary voltage of $3 \mathrm{kV}$. Tandem mass spectra were acquired in Fast-DDA (Data Directed Analysis) mode so that the two most abundant ions in full scan MS would trigger tandem mass spectrometry $\left(\mathrm{MS}^{2}\right)$. The TOF mass analyzer was calibrated using phosphoric acid in 1:1 (v:v) acetonitrile: $\mathrm{H}_{2} \mathrm{O}$ from 50 to $1500 \mathrm{~m} / \mathrm{z}$ to obtain mass accuracy within $3 \mathrm{ppm}$. The Synapt parameters were optimized using a chlorogenic acid standard as follows: the sample cone was set at $20 \mathrm{~V}$, the source and desolvation temperature were set at 120 and $600{ }^{\circ} \mathrm{C}$, respectively. Each sample was processed with MassLynx (V4.1) software. 
In a second step, area of the absorbance peak of each hydroxycinnamic acid was integrated at ACCEPTED MANUSCRIPT

$326 \mathrm{~nm}$ (maximal absorbance of CGA) and expressed as equivalent absorbance of the authentic L-chicoric acid standard (Sigma-Aldrich, Munich, Germany). Compounds were identified by their retention times, UV absorbance spectra, and MS fragmentation pattern and numbered in conformity with the IUPAC numbering system (IUPAC, 1976). For peak assignment, we took as references LC-MS/MS characterizations from Lin and Harnly (2008), Jaiswal and Kuhnert (2011), Maruta et al. (1995). Isomers were assigned by using the appropriate standards (chlorogenic acid, caffeic acid). Since other caffeoylquinic acid derivatives were not commercially available, they were identified by comparison with chromatograms of plants belonging to Asteraceae: Arctium lapa L. root and shoot extracts, Arnica montana L. flower extract, Cynaria scolymus L. leaves, Lactuca sativa L. leaves, Taraxacum officinale WEB. ex WIGG. Comparison to the leaf extract from Coffea canephora and Ilex paraguariensis was also necessary for dimethoxycinnamoyl-caffeolquinic acids (Alonso-Salces et al., 2009).

\subsection{In vivo experiments}

Experiments were performed in male Wistar rats from Charles River Laboratory (Lyon, France) and maintained on a $12 \mathrm{~h} / 12 \mathrm{~h}$ light dark schedule. Institutional guidelines for animal care and use were followed and the ethical committee Languedoc-Roussillon agreed our protocol (number 101). Diabetes was obtained by intraperitoneal injection of STZ at the dose of $65 \mathrm{mg} \cdot \mathrm{kg}^{-1}$ in rats weighing 300-320 g and thereafter maintained in individual metabolic cages. Seven days after diabetes induction, animals were divided in three groups ( four animals by group). The first group received a daily intraperitoneal (IP) administration of NCRAE at the dose of $15 \mathrm{mg} \cdot \mathrm{kg}^{-1}$ dissolved in saline for 7 days. The second cohort of diabetic rats were treated by IP injections for 7 days with the SCCAM $\left(15 \mathrm{mg} \cdot \mathrm{kg}^{-1}\right)$. The last group of diabetic animals received only IP saline as controls. During the treatments, we studied the time course of the following parameters: body weight, food intake, glycosuria/24 $\mathrm{h}$ and glycemia. At the end of the treatments, all animals were submitted to an 
oral glucose tolerance test (OGTT, glucose $3 \mathrm{~g} \cdot \mathrm{kg}^{-1}$ ). Blood samples were collected from the ACCEPTED MANUSCRIPT

tail vein of unfasting rats for plasma glucose determinations. For OGTT, animals were fasted

for $4 \mathrm{~h}$. Plasma and urinary glucose determinations were performed using the Glucose GOD-

PAP kit (BIOLABO SA, France). Results are expressed as $\mathrm{mg} \cdot \mathrm{dL}^{-1}$ for glycemia. In addition, for a better analysis of the time course of glycemia, values were calculated in $\%$ from basal values. Glycosuria evaluations were expressed as the urinary volume per $24 \mathrm{~h}$ x urinary glucose concentrations $(\mathrm{g} / 24 \mathrm{~h})$.

\subsection{Determination of total polyphenol content}

Total polyphenol content was determined by using the Folin-Ciocalteu reagent (Singleton and Rossi, 1965). Samples $(50 \mu \mathrm{g})$ was diluted in a final volume of $1 \mathrm{~mL}$ with $0.2 \mathrm{~N}$ of FolinCiocalteu reagent in water and were incubated in the dark at ambient temperature for 30 minutes. Discoloration was estimated by spectrophotometry analysis at $665 \mathrm{~nm}$. Gallic acid (GA) was used as the standard for curve calibration. The total phenol content of extracts was expressed as mg of GAE (equivalents GA) per g of dry extract.

\subsection{2-Glucose uptake test on L6 cells.}

L6 rat myocyte cells (LGC Promochem, France) were cultured in 12-well plates as previously described by Tousch et al. (2008). Briefly, on the day of the experiment, cells were first starved during $4 \mathrm{~h}$ in DMEM supplemented with 0.1\% BSA and then incubated during one hour in KRB supplemented with $0.1 \%$ BSA, $5 \mathrm{mM}$ glucose in the absence or in the presence of $100 \mathrm{nM}$ insulin. The two compounds at $50 \mu \mathrm{g} \cdot \mathrm{mL}^{-1}$ were tested in the presence of $100 \mathrm{nM}$ insulin. Cells were then gently washed and then incubated in $1 \mathrm{ml} \mathrm{KRB}$ containing $0.5 \mu \mathrm{Ci}$ $\left[{ }^{3} \mathrm{H}\right]$ deoxyglucose per well. Uptake was stopped by three washings in cold PBS and cells were lysed in $0.1 \mathrm{~N} \mathrm{NaOH}$. Radioactivity was measured and total protein concentration evaluated by a Bradford method (Bradford, 1976); results are expressed in cpm . mg protein ${ }^{-1}$ $.1 \mathrm{~min}^{-1}$. 


\section{ACCEPTED MANUSCRIPT}

\subsection{Survival test at an $\mathrm{H}_{2} \mathrm{O}_{2}$ oxidative stress on $\mathrm{L} 6$ cells.}

The L6 cell culture has been managed as described above. Cells were seeded in 96-well plates $\left(10^{4}\right.$ cells per well). On day 4 , the culture medium was changed by an DMEM supplemented with FCS, cocktail medium and with the different extracts at the final concentration of 50 $\mu \mathrm{g} \cdot \mathrm{mL}^{-1}$ during $12 \mathrm{~h}$. The next day, the cells were washed twice by $200 \mu \mathrm{L}$ per well of KrebsRinger bicarbonate buffer, $0.1 \%$ BSA and then placed in the same buffer (200 $\mu \mathrm{L}$ per well) with or without $\mathrm{H}_{2} \mathrm{O}_{2}$ at $40 \mu \mathrm{M}$. After three hours of incubation at $37^{\circ} \mathrm{C}$ in a $5 \% \mathrm{CO}_{2}$ chamber, cells were washed once by PBS and incubated 5 min in $100 \mu \mathrm{L}$ of Trypan-blue (Sigma-Aldrich) solution diluted by 3 with PBS. The trypan-blue solution was eliminated and the cell layers were visualized by Stereo Zoom Microscope for Large Fields with 16 x zoom (Axio Zoom.V16, Zeiss) with a magnification of $40 \%$. The images were checked in and the blue color densities were calculated using ImageJ 1.48v (Image Processing and Analysis in Java: https://imagej.nih.gov/ij/) software (Schneider et al., 2012). The data are expressed as \% of mortality.

\subsection{Evaluation of the antioxidant capacities}

We used both the DPPH (2,2-diphenyl-1-picryl-hydrazyl-hydrate) and the ORAC (Oxygen Radical Absorbance Capacity) tests. For DPPH test, we have used 100 nmoles of DPPH by assay with different quantities of samples. The decrease of absorbance at $517 \mathrm{~nm}$ were quantified on spectrophotometer as described by Villano et al. (2007). The free radical scavenging activity of an extracts is defined by the $\mathrm{IC}_{50}$, i.e., the quantity of sample needed to obtain $50 \%$ of inhibition of the DPPH absorbance. Using quercetin standard (with an $\mathrm{IC}_{50}$ of $20 \mu \mathrm{g} \cdot \mathrm{mL}^{-1}$ in our conditions), we have been also expressed the results in nmole of quercetin equivalent $(\mathrm{QE})$ per mg of sample (dry material).

The ORAC test was estimated with the OxiSelect ${ }^{\mathrm{TM}}$ ORAC Assay kit (Cell Biolabs, Inc.) (Huang et al., 2002). All assays have been performed using a final concentration of 
$10 \mu \mathrm{g} \cdot \mathrm{mL}^{-1}$ of both NCRAE and other compounds. Inhibition of 2,2'-azobis-(2ACCEPTED MANUSCRIPT

methylpropionamidine) dihydrochloride (AAPH) oxidation of the antioxidant compounds led to a reduction of fluorescein fluorescence quenching measured using the Infinite 200Pro spectrofluorimeter (TECAN). Using Trolox as standard, the antioxidant activities were expressed as nmole of Trolox equivalent (TE) per mg of sample (dry material).

\subsection{Data analysis}

Statistical analyses were performed using analysis of variance. In vitro data are expressed as mean $\pm \mathrm{SD}$ and in vivo data as means $\pm \mathrm{SEM}$. Difference were considered significant at $\mathrm{p}<$ $0.05(*)$ or $\mathrm{p}<0.01(* *)$ or $\mathrm{p}<0.001(* * *)$ using the Statgraphics $18^{\circledR}$ software.

\section{Results}

\subsection{Chemical analysis of NCRAE content (Table 1 and 2)}

Using the Folin-Ciocalteu method, we have observed that NCRAE contains essentially polyphenols (1390 mg GAE/g of dry extract). LC-MS mass spectrometry analysis has allowed us to assign and characterize these compounds: the data are shown in Table 1 and Table 2. Twenty-three peaks were separated with the column and the chromatographic gradient we used. Most of the peaks showed absorbance spectra with two bands at 220$245 \mathrm{~nm}$ and $315-335 \mathrm{~nm}$ separated by a shoulder at $290-300 \mathrm{~nm}$, which were characteristic of hydroxycinnamic acids (P1 to P9, P12 to P16, P19 to P22). Four peaks exhibited absorbance spectra with two maximum bands at $254-256 \mathrm{~nm}$ and $352-354 \mathrm{~nm}$ (P10, P11, P17, P18) characteristic of flavonoids. Peaks P7, P10, P11 and P13 were unequivocally identified on the basis of their concordance with retention times, UV absorbance spectra, and $\mathrm{MS}^{2}$ fragment proportions to pure authentic standards. Other peaks were tentatively assigned based on bibliographic data. Sesquiterpene lactones (three classes of bitter) previously identified in Cichorium intybus L. (Bais and Ravishankar, 2001; Al-Snafi, 2016) were completely missing in NCRAE. The 8-deacetylmatricarin-8-O-sulfate recently found in Cichorium spinosum L. 
(Brieudes et al., 2016) was not found in NCRAE. Similarly, saponins such as cynaragenins ACCEPTED MANUSCRIPT

also identified in $C$. intybus were not identified in NCRAE.

\subsubsection{Assigment of hydroxycinnamic acid derivatives}

Tartaric acid esters:

Peaks P1, P2, P7, P8 and P9 shared the daughter ion at $\mathrm{m} / \mathrm{z} 149.0086$ corresponding to [tartaric acid-H] ${ }^{-}$fragment ion. This one gave under $\mathrm{MS}^{2}$ fragmentation three fragments ions at $\mathrm{m} / \mathrm{z} 131$ [tartaric acid- $\left.\mathrm{H}_{2} \mathrm{O}-\mathrm{H}\right]^{-}$, at $\mathrm{m} / \mathrm{z} 103$ and at m/z 87. Peak $\mathrm{P} 1$ and $\mathrm{P} 2 \mathrm{~m} / \mathrm{z} 311.0407$ $[\mathrm{M}-\mathrm{H}]^{-}$yielded $\mathrm{MS}^{2}$ fragment ions at m/z 179 [caffeic acid-H] ${ }^{-}$and m/z 135 [caffeic acid$\left.\mathrm{CO}_{2}-\mathrm{H}\right]^{-}$, and were identified as caffeoyl-O-tartaric acid isomers, also named caftaric acid isomers. Peak 2 predominantly formed the adduct $\mathrm{m} / \mathrm{z} 623$ [2 caftaric acid $-\mathrm{H}]^{-}$in $\mathrm{MS}^{1}$ experiment, already observed by Schütz et al. (2005) for the trans isomer. Consequently, peak 1 was consistent with the cis-caftaric acid and peak 2, with the trans-caftaric acid. Peaks 7,8 , 9 exhibited absorbance spectra shapes similar to trans-chicoric acid ( $L$-chicoric acid) with the pseudo-molecular ion m/z 473.0699 of dicaffeoyltartaric acid esters and exhibited daughter ions at $\mathrm{m} / \mathrm{z} 311,293,179,149$. They corresponded to $\mathrm{m} / \mathrm{z} 311$ [caffeoyltartaric acid-H] $^{-}, 293$ [caffeoyltartaric acid- $\left.\mathrm{H}_{2} \mathrm{O}-\mathrm{H}\right]^{-}, 179$ [caffeic acid-H] $]^{-}, 149$ [tartaric acid-H] $]^{-}$This fragmentation behavior was in accordance with previous reports (Bergeron et al., 2002; Schultz et al., 2005). Peak 7 was positively identified as $L$-chicoric acid using pure standard. P7 is the preponderant compound of the extract. Peaks 8 and 9 may correspond to its two other diastereoisomers, $D$-chicoric acid and meso-chicoric acid described by Buiarelli et al. (2010) and Carazzone et al. (2013). Similarly to Khoza et al. (2016), we observed that the fragmentation pattern of the three isomers is tightly similar in electrospray ionization conditions. Peak 9 was attributed to the meso isomer because of its lower amount of fragment $\mathrm{m} / \mathrm{z} 293$ previously described (Llorach et al., 2008). No guarantee can be given that the formation of these two later isomers was not occurring during extraction, elution or electrospray ionization processes. Peaks 8 and 9 are in much reduced amount compared to $L$ - 
chicoric acid. Peak P6 exhibited a parent ion m/z 491.0794, which formed in $\mathrm{MS}^{2}$ experiment, ACCEPTED MANUSCRIPT

two fragment ions at m/z 293 and m/z 329, and a fragmentation pattern already found for a tartaric acid derivative of root and herb juice of Taraxacum officinale Web. Ex Wigg. (Schultz et al., 2005) and root extract of Taraxacum formosanum Kitam (Chen et al., 2012). Presence of fragment ion $\mathrm{m} / \mathrm{z} 329$ indicated the loss of a caffeic moiety, which was confirmed by presence of fragment ions $\mathrm{m} / \mathrm{z} 179$ [caffeic acid-H] ${ }^{-}$and $\mathrm{m} / \mathrm{z} 135$ [caffeic acid- $\left.\mathrm{CO}_{2}-\mathrm{H}\right]^{-}$. $\mathrm{MS}^{3}$ fragmentation of ion $\mathrm{m} / \mathrm{z} 329$ yielded m/z 311 [caffeoyltartaric acid-H] , m/z 149 [tartaric acid-H] and m/z 135 [caffeic acid- $\left.\mathrm{CO}_{2}-\mathrm{H}\right]^{-}$. Presence of fragment m/z 293 was attributed to the loss of dihydroxyphenyllactic acid plus $\mathrm{H}_{2} \mathrm{O}$ [M- dihydroxyphenyllactic acid - $\left.\mathrm{H}_{2} \mathrm{O}-\mathrm{H}\right]^{-}$by Schütz et al. (2005) and Chen et al. (2012). In addition, peak 6 had similar absorbance spectrum to peak 8 previously described (Schultz et al, 2005) for dandelion $(246 \mathrm{~nm}, 300 \mathrm{sh}, 332 \mathrm{~nm})$. The minor peak P6 was consistent with caffeoyldihydroxyphenyllactoyltartaric acid.

\section{Caffeoylquinic acid esters :}

Peaks 12, 13, 14, 16 and 19 exhibited absorbance spectra shapes similar to chlorogenic acid with the daughter ion at m/z 191.0563 corresponding to [quinic acid-H]'. This one gave under $\mathrm{MS}^{\mathrm{n}}$ fragmentation two fragments ions at $\mathrm{m} / \mathrm{z} 127$ [quinic acid-CO-2 $\mathrm{H}_{2} \mathrm{O}-\mathrm{H}$ ] ${ }^{-}$and $\mathrm{m} / \mathrm{z} 173$ [quinic acid- $\left.\mathrm{H}_{2} \mathrm{O}-\mathrm{H}\right]^{-}$. Monocaffeoylquinic acids (parent ion of $\mathrm{m} / \mathrm{z}$ 353.0877) and dicaffeoylquinic acids (parent ion of $\mathrm{m} / \mathrm{z}$ 515.1194) were assigned using the identification hierarchical key of quinic acid derivatives proposed by Clifford et al. (2006). Peaks 12 and 16 displayed a fragment ion at $\mathrm{m} / \mathrm{z} 173$ [quinic acid $\left.-\mathrm{H}_{2} \mathrm{O}-\mathrm{H}\right]^{-}$base peak, characteristic of the caffeoyl group esterified to the 4-OH position of quinic acid. When caffeoyl groups are esterified to the $3-\mathrm{OH}$ position and 5-OH position of quinic acid, the $\mathrm{m} / \mathrm{z} 191$ [quinic acid-H] fragment ion remains the base peak and the signal of $\mathrm{m} / \mathrm{z} 179$ [caffeic acid-H] $^{-}$fragment ion is more significant for 3-OH acyled position of the quinic acid (Peak 13 and 14). The minor peak $\mathrm{P} 19$ had a parent ion $\mathrm{m} / \mathrm{z} 615.1428$ corresponding to $\mathrm{C}_{29} \mathrm{H}_{28} \mathrm{O}_{15}$ and had 3 daughter ions, m/z 515 [dicaffeoylquinic acid-H], m/z 353 [caffeoylquinic acid-H]', and m/z 453 suggesting 
the fragment [caffeoyl-succinoylquinic acid-H] . We observed the presence of a secondary ACCEPTED MANUSCRIPT

peak at $\mathrm{m} / \mathrm{z} 335$ [caffeoylquinic acid- $\left.\mathrm{H}_{2} \mathrm{O}-\mathrm{H}\right]^{-}$in the $\mathrm{MS}^{2}$ spectrum, which indicated that the succinoyl group is esterified at the 4-acyl chlorogenic acid (Jaiswal and Kuhnert, 2011). We found that P19 correspond to 1,5-di-O-caffeoyl-3-O-succinoylquinic acid previously described in Arctium lapa L. by Tousch et al. (2014). Peak 20 and 21 shared a pseudomolecular ion $\mathrm{m} / \mathrm{z} 543.1508[\mathrm{M}-\mathrm{H}]^{-}$corresponding to $\mathrm{C}_{27} \mathrm{H}_{28} \mathrm{O}_{12}$ characteristic of dimethoxycinnamoyl-caffeoylquinic acids (Alonso-Salces et al., 2009), also referred as methylferuloyl-O-caffeoylquinic acid (Jaiswal and Kuhnert, 2011). They shared the secondary ion $\mathrm{m} / \mathrm{z} 381.1191[\mathrm{M}-\mathrm{H}]^{-}$, corresponding to the loss of the methylferuloyl moiety. This is confirmed in $\mathrm{MS}^{2}$ experiment by the appearance of fragment ions $\mathrm{m} / \mathrm{z} 207$ [dimethoxycinnamic acid-H] ${ }^{-}$and $\mathrm{m} / \mathrm{z} 103$ [dimethoxycinnamic acid- $\left.\mathrm{H}_{-} \mathrm{H}_{2} \mathrm{O}-2 \mathrm{CH}_{3}{ }^{\bullet}-2 \mathrm{CO}\right]^{-}$. The absence of the secondary ion $\mathrm{m} / \mathrm{z} 349$ indicated that the second acyl group esterified on quinic acid is not a dihydroxy-methoxy-cinnamic acid residue. Therefore, according to the identification key based on the fragmentation pattern of dimethoxycinnamoyl-caffeoylquinic acids in Collision Induced Dissociation-MS-MS, established by Alonso-Salces et al. (2009), peaks 20 and 21 were tentatively assigned 3-O-methylferuloyl-4-O-caffeoylquinic acid and 3$O$-methylferuloyl-5-O-caffeoylquinic acid, respectively.

\subsubsection{Assigment of flavonoids and coumarins.}

Analysis by $\mathrm{MS}^{2}$ fragmentation of peaks $\mathrm{P} 10$ and $\mathrm{P} 17$ resulted in a common ion at m/z 301.0353. Its $\mathrm{MS}^{3}$ fragmentation gave 4 fragments: m/z $271\left(\left[\mathrm{M}-\mathrm{H}-\mathrm{CH}_{2} \mathrm{O}\right]^{-}\right), \mathrm{m} / \mathrm{z} 255([\mathrm{M}-$ $\left.\left.\mathrm{H}-\mathrm{H}_{2} \mathrm{O}-\mathrm{CO}\right]^{-}\right), \mathrm{m} / \mathrm{z} 179\left(\left[{ }^{1,2} \mathrm{~A}-\mathrm{H}\right]^{-}\right)$and ions at $\mathrm{m} / \mathrm{z} 151\left({ }^{1,2} \mathrm{~A}-\mathrm{CO}\right)$, originating from a retroDiels-Alder (RDA) reaction similarly to that from the fragmentation of a standard solution of quercetin. We observed that Peak P10 had a parent ion m/z $477.0644[\mathrm{M}-\mathrm{H}]^{-}$and that its fragment ion $\mathrm{m} / \mathrm{z} 301$ corresponded to the loss of the glucuronide moiety (176 amu). In $\mathrm{MS}^{2}$ experiment, P10 conformed to fragmentation of quercetin-3-O-glucuronide, since quercetin-4$O$-glucuronide and quercetin-7-O-glucuronide have additional characteristic fragments not found in this extract (Davis et al., 2006). Therefore, peak P10 was assigned to quercetin-3-O- 
glucuronide. Peak P17 had a parent ion m/z 505.0994 [M-H] $]^{-}$and yield to m/z 463 in $\mathrm{MS}^{2}$ ACCEPTED MANUSCRIPT

and the loss of 206 amu, which indicates a hexoside moiety (162 amu) linked to an acetyl group (44 amu). It could correspond to quercetin-7-O-(6"-acetyl-glucoside) since it has already been found in Cichorium (Llorach et al., 2008) and Lettuce (Ribas-Agusti et al., 2011). Analysis by $\mathrm{MS}^{2}$ fragmentation of peaks $\mathrm{P} 11$ and $\mathrm{P} 18$ resulted in the ion at $\mathrm{m} / \mathrm{z}$ 285.0435. Fragmentation of the ion at $\mathrm{m} / \mathrm{z} 285$ gave a fragment ion at $\mathrm{m} / \mathrm{z} 255$ (loss of 30 amu, $\left.\left[\mathrm{Y}_{0}^{-}{ }^{-} \mathrm{CH}_{2} \mathrm{OH}\right]^{-}\right)$which is characteristic of kaempferol. The loss of $176 \mathrm{amu}$ in $\mathrm{MS}^{2}$ experiment by Peak P11 suggests the loss of glucuronide moiety. Peak P11 was assigned to kaempferol-7-O-rutinoside and positively confirmed by its authentic standard. Peak P18 had a pseudo-molecular ion m/z 593.1511 [M-H], producing secondary ions m/z 285 [kaempferol$\mathrm{H}^{-}$and $\mathrm{m} / \mathrm{z} 447$ [(kaempferol+hexose)-H] $]^{-}$, It was assigned to an undetermined kaempferol$O$-hexosyl-rhamnoside. Peak P22 had a parent ion $\mathrm{m} / \mathrm{z} 339.0650[\mathrm{M}-\mathrm{H}]^{-}$corresponding to $\mathrm{C}_{15} \mathrm{H}_{15} \mathrm{O}_{9}$, and the daughter ions at $\mathrm{m} / \mathrm{z} 177.0193\left(\mathrm{C}_{9} \mathrm{H}_{5} \mathrm{O}_{4}\right)$ corresponding to the loss of hexoside moiety. The $\mathrm{MS}^{2}$ experiment yielded to $\mathrm{m} / \mathrm{z} 133.0301$ [esculetin-H]'. Peak 22 was assigned to esculin and positively identified using authentic standard. P22 is a common coumarin in Cichorium species (Kisiel and Michalska, 2002) also name cichoriin.

In summary, NCRAE is essentially composed of $72.4 \%$ of caffeoyl tartaric acids with chicoric (dicaffeoyls) acids that represent $64.2 \%$ of the extract and $19.6 \%$ of caffeoyl quinic acids (mono and diCQAs) among which $2.1 \%$ of methylferuloyl-O-caffeoylquinic acid. The rest of the NCRAE content is flavonoïds derivatives $(6.6 \%)$. These results have led to the preparation of the SCCAM solution combining $70 \%$ of CRA and $30 \%$ of CGA, close to the 0.3 CQAs/CRA ratio of NCRAE.

\subsection{In vivo experiments.}

\subsubsection{Evidence of the obtaining of a severe diabetic state}

Seven days after STZ injection in rats, glycemia raised from $108 \pm 3$ to $561 \pm 21 \mathrm{mg}^{\mathrm{dL}} \mathrm{dL}^{-1}$ and plasma insulin dropped from $3.78 \pm 0.37$ to $0.38 \pm 0.04$ ng.mL $\mathrm{mL}^{-1}$ i.e. a loss of $90 \%$. 


\section{ACCEPTED MANUSCRIPT}

\subsubsection{Time course of the physiological parameters}

The first consequences of the diabetes were a stop in the gain of body weight and a clear increase in food intake $(\mathrm{p}<0.01)$ (Fig. 1). The daily administration of NCRAE or SCCAM did not modify these evolutions (Fig. 1A, 1B). After STZ injection, glycosuria appeared and raised to high values for all animals. NCRAE or SCCAM treatments induced a significant stabilization (Fig. 1C). So at the 6th day glycosurias of treated rats were $12.9 \pm 0.6$ and $14.3 \pm$ $0.5 \mathrm{~g} / 24 \mathrm{~h}$ respectively under NCRAE or SCCAM administrations versus $18.5 \pm 1.3 \mathrm{~g} / 24 \mathrm{~h}$ for control diabetic animals $(\mathrm{p}<0.01)$.

\subsubsection{Effect on blood glucose levels}

Time course of hyperglycemia.

In control diabetic rats, we observed a continuous hyperglycemia of about $600 \mathrm{mg} . \mathrm{dL}^{-1}$ (Fig. 2). NCRAE treatment induced a clear decrease in hyperglycemia from the $2^{\text {th }}$ to the $6^{\text {th }}$ day $\left(433 \pm 33 \mathrm{mg} \cdot \mathrm{dL}^{-1}\right)(\mathrm{p}<0.01)$. In contrast SCCAM treatment did not significantly change the time course of hyperglycemia (Fig. 2A and 2B). Thus, we only observed a reduction of hyperglycemia with NCRAE administration $\left(-18 \%\right.$ on the $6^{\text {th }}$ day, $\left.\mathrm{p}<0.01\right)$ (Fig 2B).

\section{Oral glucose tolerance test (OGTT) (Fig. 3).}

The oral charge in glucose induced a clear increase in hyperglycemia in all diabetic animals. However, this increase is slight during the first 30 minutes with SCCAM. From 90 minutes a more rapid decrease in hyperglycemia is observed in both groups of treated rats. So at 180 minutes hyperglycemia was $412 \pm 17$ and $415 \pm 17 \mathrm{mg}^{-\mathrm{dL}^{-1}}$ respectively, for NCRAE and SCCAM treated animals versus $530 \pm 40 \mathrm{mg} \cdot \mathrm{dL}^{-1}$ for control diabetic rats $(\mathrm{p}<0.001)$.

\subsection{In vitro experiments (Fig.4).}

\subsubsection{Insulin sensitizing investigations on L6 cells.}

The results were reported on the Fig.4A: As expected, insulin (100 nM) increased basal glucose uptake in L6 cells. Addition of NCRAE significantly increased glucose uptake at 50 
mg.mL $L^{-1}(p<0.05)$ which is in agreement with our previous report (Tousch et al., 2008). At the ACCEPTED MANUSCRPT

same concentration of $50 \mu \mathrm{g} \cdot \mathrm{mL}^{-1}$, SCCAM solution has also led to an increase of the glucose uptake $(\mathrm{p}<0.01)$ with a value that is close to the NCRAE values.

\subsubsection{Oxidative stress $\left(\mathrm{H}_{2} \mathrm{O}_{2}\right)$ survival test on $\mathrm{L} 6$ cells.}

L6 cells were submitted at a pretreatment with NCRAE or SCCAM during 12 hours after that the compounds are eliminated by two washes. Then, $40 \mu \mathrm{M} \mathrm{H}_{2} \mathrm{O}_{2}$ oxidative treatment are applied. The mortality of the cells is quantified using a vital trypan blue dye (Fig.4B). In these conditions, the SCCAM pretreatment did not have a significant protective effect while NCRAE pretreatment induced a low but significant protective effect with a mortality of 46.8 $\pm 3.6 \%$ comparatively in the control at $55.4 \pm 3.6 \%(\mathrm{p}<0.05)$.

\subsection{Quantification of the antioxidant capacities.}

NCRAE exhibited a DPPH-free radical scavenging with a $\mathrm{IC}_{50}$ at $61.4 \pm 1.75 \mu \mathrm{g} \cdot \mathrm{mL}^{-1}$ and a QE.mg ${ }^{-1}$ at $1077 \pm 31$ nmoles compared at SCCAM with a IC50 at $29.6 \pm 1.2 \mu \mathrm{g} \cdot \mathrm{mL}^{-1}$ and a QE.mg ${ }^{-1}$ at $2240 \pm 91$ nmoles. The ORAC (Oxygen Radical Absorbance Capacity) test results were similar to those of DPPH tests with a TE at $3619 \pm 48$ nmoles.mg ${ }^{-1}$ for NCRAE and $7020 \pm 69$ nmoles.mg ${ }^{-1}$ for SCCAM. So, the chemical antioxidant capacity of SCCAM is clearly higher that NCRAE.

\section{Discussion}

The present study demonstrates that NCRAE, a natural caffeoyl derivatives extract, is able to reduce basal hyperglycemia and to improve oral glucose tolerance in streptozotocin diabetic rats, pointing out that NCRAE may be considered of interest for the treatment of diabetes.

The chemical analysis by LC-MS has allowed to obtain interesting information on the NCRAE composition, essentially composed of caffeoyltartaric acid isomers with $L$-chicoric acid $(64.2 \%)$ and its other isomers and derivatives esters of caffeoylquinic acids (CQAs) (19.6\%). The presence of CQAs under mono and di-caffeoylquinic acids forms has been previously described by Milala et al. (2009). The high content of chicoric acid rather 
described in lower quantity in roots than in the aerial parts of chicory (Al-Snafi et al., 2016; ACCEPTED MANUSCRIPT

Brieudes et al., 2016) shows that the chromatography procedure we used allows to concentrate the caffeoyl derivatives. The presence of quercetin-3-O-glucuronide in NCRAE was described in the roots of chicory (Schultz et al., 2005). We can also note the presence of Ferulic acid derivatives at a lower proportion $(2.1 \%)$.

STZ diabetes induced rat model is known as an appropriate model to search for potential therapies since it mimics several metabolic disorders observed in human diabetes (Urgate et al., 2012). In our STZ model, the increase in food intake and the absence in body weight gain are in agreement with the previous report (Akbarzadeh et al., 2007). STZ injection induced a severe diabetes, i.e., insulinemia dramatically dropped (-90\%) due to the fall in the pancreatic insulin content (Masiello et al., 1998). In these conditions, the antidiabetic effect of NCRAE cannot be the consequence of a pancreatic insulinotropic action previously reported on INS1 cells (Tousch et al, 2008). One possibility to explain the antidiabetic property of NCRAE could be an insulin sensitizing effect on peripheral tissues as muscles. Indeed, we have previously demonstrated that NCRAE has the ability in vitro to enhance glucose uptake in L6 muscle cell line and does not act on hepatic glucagon-induced glycogenolysis via hepatic glucose 6 phosphatase activity (Azay-Milhau et al., 2013). The results on L6 muscular cells are in agreement with the report of Lee et al. (2007) on the same in vitro model. Here, we have shown that SCCAM possess a similar capacity that NCRAE to enhance the glucose uptake on the L6 cells, indicating the value of the mixture of chicoric acid and chlorogenic acid on insulin sensitivity. The presence of Ferulic acid derivatives in NCRAE can be beneficial since trans-Ferulic acid has been reported to exert an antidiabetic effect by modulating insulin signaling pathway in the liver of type 2 diabetic rats (Narasimhan et al., 2015). The delayed improvement in OGTT can be due to the insulin sensitizing action of NCRAE by caffeoyltartaric acid derivatives and the stabilization of glycosuria may be related to the decrease in basal hyperglycemia. 
Regarding the SCCAM treatment, it did not change basal hyperglycemia in STZ diabetic rats. ACCEPTED MANUSCRIPT

However an immediate and clear improvement in OGTT was observed. The capacity of CGA to enhance glucose uptake in peripheral tissues and to reduce hepatic glycogenolysis (Meng et al., 2013) by inhibition of glucose 6-phosphatase activity (Hemmerle et al., 1997) can explain the stabilization in glycosuria and OGTT improvement with SCCAM treatment. Moreover, increasing evidence showed that oxidative stress participates in pathogenesis of diabetes (Maritim et al., 2003; Msolly et al., 2013; Nikolic et al., 2014). So, it has been necessary to consider the antioxidant capacities of the two products. For their antioxidant potential, the two compositions revealed significant activities, around twice for SCCAM. Consequently, a direct antioxidant effect cannot be responsible of the basal glycemia decrease observed only with NCRAE. In regard to the capacity of cell protection against $\mathrm{H}_{2} \mathrm{O}_{2}$ oxidative stress, the treatment of 12 hours with NCRAE induced a small decrease of mortality while no effect are observed with SCCAM. Moreover in our experiments conditions, the chemical antioxidant capacity does not have any correlation with the cellular protective capacity of these compositions against $\mathrm{H}_{2} \mathrm{O}_{2}$.

Through a better control of hyperglycemia known to induce oxidative stress (Esposito et al., 2002; Ceriello and Testa, 2009), NCRAE could have a protective effect on the evolution course and complications of diabetes.

In conclusion, we demonstrated that NCRAE, a natural extract rich in CRA from chicory (Cichorium intybus) improves glucose tolerance and reduces the basal hyperglycemia in STZ diabetic rats. These interesting effects of NCRAE are the result of the association of CRA and CGA but also at the presence of other hydroxycinnamic acids.

\section{Declaration of interest}

The authors declare no conflict of interest and no financial interference with the IP rights of the indigenous people. 


\section{Author Contributions}

\section{ACCEPTED MANUSCRIPT}

D.T., K.F. and L.P.R.B. designed the research. L.P.R.B. and G.C. performed the LC-MS analysis. K.F. and A.A. performed the in vitro and in vivo experiments. P.P. and J.A.-M. performed the in vivo experiment. D.T., P.P. and A.D.L. analyzed the data and wrote the manuscript. All authors reviewed the manuscript.

\section{Acknowledgments}

We sincerely thank Dr. Gérard Ribes for consenting to give us precious scientific advice and his help to the redaction of this publication.

\section{REFERENCES}

Akbarzadeh, A., Narouzian, D., Mehrabi, M.R., Jamshidi, Sh., Farhangi, A., Allah Verdi, A., Mofidian, S. M. A., Lame Rad, B., 2007. Induction of diabetes by streptozotocin in rats. Indian J. Clin. Biochem. 22, 60-64.

Alonso-Salces, R.M., Guillou, C., Berrueta, L.A., 2009. Liquid chromatography coupled with ultraviolet absorbance detection electrospray ionization, collision induced dissociation and tandem mass spectrometry on a triple quadripole for the on-line characterization of polyphenols and methylxanthines in green coffee beans. Rapid Commun. Mass Spectrom. 23, 363-383.

Al-Snafi, A.E., 2016. The contents and Pharmacological Importance of Corchorus capsularis: A Review. Chemist. Res. J. 1, 9-16.

Azay-Milhau, J., Ferrare, K., Leroy, J., Aubaterre, J., Tournier, M., Lajoix, A.-D., Tousch, D., 2013. Antihyperglycemic effect of a natural chicoric acid extract of chicory (Cichorium intybus L.): A comparative in vitro study with the effects of caffeic and ferulic acids. J. Ethnopharm. 150, 755-760. 
Bais, H. P., Ravishankar G. A., 2001. Cichorium intybus L. - cultivation, processing, utility, ACCEPTED MANUSCRIPT

value addition and biotechnology, with an emphasis on current status and future prospects. J. Sci. Food Agric. 81, 467-484.

Bergeron, C., Gafner, S., Batcha, L.L., Angerhofer, C. K., 2002. Stabilization of caffeic acid derivatives in Echinacea purpurea L. glycerin extract. J. Agric. Food Chem. 50, 39673970.

Bradford, M.M., 1976. A dye binding assay for protein. Anal. Biochem. 72, 248-254.

Brieudes, V., Angelis, A., Vougogiannopoulou, K., Pratsinis, H., Kletsas, D., Mitakou, S., Halabalaki, M.; Skaltsounis, L.A., 2016. Phytochemical analysis and antioxidant potential of the phytonutrient-rich decoction of Cichorium spinosum and C. intybus. Planta Med. 82, 1070-1078.

Buiarelli, F., Coccioli, F., Merolle, M., Jasionowska, R., Terracciano, A., 2010. Identification of hydroxycinnamic acid-tartaric acid esters in wine by HPLC-tandem mass spectrometry. Food Chem. 123, 827-833.

Carazzone, C., Mascherpa, D., Gazzani, G., Papetti, A., 2013. Identification of phenolic constituents in red chicory salads (Cichorium intybus) by high-performance liquid chromatography with diode array detection and electrospray ionization tandem mass spectrometry. Food Chem. 138, 1062-1071.

Ceriello, A., Testa, R., 2009. Antioxidant anti-inflammatory treatment in type 2 diabetes. Diabetes Care. 32 Suppl 2, S232-S236.

Chen, H.J., Inbaraj, B.S., Chen, B.H., 2012. Determination of phenolic acids and flavonoids in Taraxacum formosanum Kitam by liquid chromatography-tandem mass spectrometry coupled with a post-column derivatization technique. Int. J. Mol. Sci. 13, 260-285. 
Cheng, J.T., Lin, L.M., Tzeng, T.E., Chen, W.C., Hayakama, S., Yamamoto, T., 2003. ACCEPTED MANUSCRIPT

Release of beta-endorphin by caffeic acid to lower plasma glucose in streptozotocin induced diabetic rats. Horm. Metab. Res. 35, 251-258.

Clifford, M.N., Knight, S., Surucu, B., Kuhnert, N., 2006. Characterization by LC-MS ${ }^{\mathrm{n}}$ of four new classes of chlorogenic acids in green coffee beans: dimethoxycinnamoylquinic acids, diferuloylquinic acids, caffeoyl-dimethoxycinnamoylquinic acids and feruloyldimethoxycinnamoylquinic acids. J. Agric. Food Chem. 54, 1957-1969.

Davis, B.D., Needs, P.W., Kroon, P.A., Brodbelt, J.S., 2006. Identification of isomeric flavonoid glucuronides in urine and plasma by metal complexation and LC-ESI-MS/MS. J. Mass Spectrom. 41, 911-920.

Esposito, K., Nappo, F., Marfella, R., Giugliano, G., Giugliano, F., Ciotola, M., Quagliaro, L., Ceriello, A., Giugliano, D., 2002. Inflammatory cytokine concentrations are acutely increased by hyperglycemia in humans: role of oxidative stress. Circulation. 106, 20672072.

Fraisse, D., Felgines, C., Texier, O., Lamaison, J.L., 2011. Caffeoyl derivatives major antioxidant compounds of some wild herbs of the Asteraceae family. Food Nutr. Sci. 2, 181-192.

Ghamarian A., Abdollahi M., Su X., Amiri A., Ahadi A., Nowrouzi A., 2012. Effect of chicory seed extract on glucose tolerance test (GTT) and metabolic profile in early and late stage diabetic rats. Daru. 20, 56-64.

Hemmerle, H., Burger, H.J., Below, P., Schubert, G., Rippel, R., Schindler, P.W., Paulus, E., Herling, A.W., 1997. Chlorogenic acid and synthetic chlorogenic acid derivatives: novel inhibitors of hepatic glucose-6-phosphate translocase. J. Med. Chem. 40, 137-145.

Huang, D., Ou, B., Hampsch-Woodill, M., Flanagan, J.A., Deemer, E.K., 2002. Development and validation of oxygen radical absorbance capacity assay for lipophilic antioxidants 
using randomly methylated beta-cyclodextrin as the solubility enhancer. J. Agric Food ACCEPTED MANUSCRIPT

Chem. 50, 1815-1821.

IUPAC Commission on the Nomenclature of Organic Chemistry (CNOC) and IUPAC-IUB Commission on Biochemical Nomenclature (CBN), 1976. Nomenclature of cyclitols. Recommendations. Biochem J. 153, 23-31.

Jaiswal, R., Kuhnert, N., 2011. How to identify and discriminate between the methyl quinates of chlorogenic acids by liquid chromatography-tandem mass spectrometry. J. Mass. Spectrom. 46, 269-281.

Jung, U.J., Lee, M.K., Park, Y.B., Jean, S.M., Choi, M.S., 2006. Antihyperglycemic and antioxydant properties of caffeic acid in db/db mice. J. Pharma. Exp. Ther. 318, 476-483.

Khoza, B.S., Gbashi, S., Steenkamp, P.A., Njobeh, P.B., Madala, N.E., 2016. Identification of hydroxylcinnamoyl tartaric acid esters in Bidens pilosa by UPLC-tandem mass spectrometry. S. Afr. J. Bot. 103, 95-100.

Kisiel, W., Michalska, K., 2002. A new coumarin glucoside ester from Cichorium intybus. Fitoterapia. 73, 544-546.

Lee, E.S., Uhm, K.O., Lee, Y.M., Han, M., Lee, M., Park, J.M., Suh, P.G., Park, S.H., Kim, H.S., 2007. CAPE (caffeic acid phenethyl ester) stimulates glucose uptake through AMPK (AMP-activated protein kinase) activation in skeletal muscle cells. Biochem Biophys Res Commun. 361, 854-858.

Leporatti, M.L., Ivancheva, S., 2003. Preliminary comparative analysis of medicinal plants used in the traditional medicine of Bulgaria and Italy. J Ethnopharmacol. 87, 123-142.

Lin, L.-Z., Harnly, J.M., 2008. Identification of hydroxycinnamoylquinic acids of Arnica flowers and burdock roots using a standardized LC-DAD-ESI/MS profiling method. J. Agric. Food Chem. 56, 10105-10114. 
Llorach, R., Martinez-Sanchez, A., Tomas-Barberan, F.A., Gil, M.I., Ferreres, F., 2008. ACCEPTED MANUSCRIPT

Characterisation of polyphenols and antioxidant properties of five lettuce varieties and escarole. Food Chem. 108, 1028-1038.

Maruta, Y., Kawabata, J., Niki, R., 1995. Antioxidative caffeoyl-quinic acid derivatives in the roots of burdock (Arctium lappa L.). J Agric Food Chem. 43, 2592-2595.

Maritim, A.C., Sanders, R.A., Watkins, J. B., 2003. Diabetes, oxidative stress, and antioxidants: A review. J. Bioch. Molecul. Toxicol. 17, 24-38.

Masiello, P., Broca, C., Gross, R., Roye, M., Manteghetti, M., Hillaire-Buys, D., Novelli, M., Ribes G., 1998. Experimental NIDDM. Development of a new model in adult rats administered streptozotocin and nicotinamide. Diabetes. 47, 224-229.

Meng, S., Cao, J., Feng, Q., Peng, J., Hu, Y., 2013. Roles of Chlorogenic acid on Regulating Glucose and Lipids Metabolism: A review. Evid Based complement Alternat Med., 2013, 801457. http://dx.doi.org/10.1155/2013/801457.

Milala, J., Grzelak, K., Król, B., Juśkiewicz, J., Zduńczyk, Z., 2009. Composition and properties of Chicorium extracts rich in fructans and polyphenols. Pol. J. Food Nutr. Sci. $59,35-43$

Msolly, A., Miled, A., Kassab, A., 2013. Hydrogen peroxide: an oxidant stress indicator in type 2 diabetes mellitus. JCvD. 1, 48-52.

Namura, E., Kashiwada, A., Hasada, A., Nakamura, K., Marishita, X., Tsimo, T., Tamiguchi, H., 2003. Synthesis of amide compounds of ferulic acid and their stimulatory effects on insulin secretion in vitro. Bioorg. Med. Chem. 11, 3807-3813.

Narasimhan, A., Chinnaiyan, M., Karundevi, B., 2015. Ferulic acid exerts its antidiabetic effect by modulating insulin-signaling molecules in the liver of high-fat diet and fructoseinduced type-2 diabetic adult male rat. Appl. Physiol. Nutr. Metab. 40, 769-781. 
Niggeweg, R., Michael, A.J., Martin, C., 2004. Engineering plants with increased levels of the ACCEPTED MANUSCRIPT

antioxydant chlorogenic acid. Nat. Biotechno. 22, 746-754.

Nikolic, D., Stanimirovic, J., Bjelogrlic, P., Isenovic, E.R., 2014. Oxidative stress and the role of antioxidative treatment in diabetes mellitus. Oxid. Antioxid. Med. Sci. 3, 9-14.

Pushparaj PN, Low HK, Manikandan J, Tan BK, Tan CH. 2007. Anti-diabetic effects of Cichorium intybus in streptozotocin-induced diabetic rats. J Ethnopharmacol. 111, 430434.

Ribas-Agustí, A., Gratacós-Cubarsí, M., Sárraga, C., García-Regueiro, J.A., Castellari, M., 2011. Analysis of eleven phenolic compounds including novel p-coumaroyl derivatives in lettuce (Lactuca sativa L.) by ultra-high-performance liquid chromatography with photodiode array and mass spectrometry detection. Phytochem. Anal. 22, 555-563.

Sato, Y., Itagaki, S., Kurokawa, T., Ogura, J., Kobayashi, M., Hirano, T., Sugawara, M., Iseki, K., 2011. In vitro and in vivo antioxidant properties of chlorogenic acid and caffeic acid. Int. J. Pharm. 403, 136-138.

Schlernitzauer, A., Oiry, C., Hamad, R., Galas, S., Cortade, F., Chabi, B., Casas, F., Pessemesse, L., Fouret, G., Feillet-Coudray, C., Cros, G., Cabello, G., Magous, R., Wrutniak-Cabello, C., 2013. Chicoric acid is an antioxidant molecule that stimulates AMP Kinase pathway in L6 myotubes and extends lifespan in Caenorhabditis elegans. PLoS ONE. 8, e78788.

Schneider, C.A., Rasband, W.S., Eliceiri, K.W., 2012. NIH Image to ImageJ: 25 years of image analysis. Nat. Methods. 9, 671- 675.

Schultz, K., Kammerer, D.R., Carle, R., Schieber A., 2005. Characterization of phenolic acids and flavonoids in dandelion (Taraxacum officinale Web. ex Wigg.) root and herb by high-performance liquid chromatography/electrospray ionization mass spectrometry. Rapid Commun. Mass Spectrom. 19, 179-186. 
Singleton, V.L. and Rossi, J.A., 1965. Colorimetry of total phenolics with phosphomolybdicACCEPTED MANUSCRIPT

phosphotungstic acid reagents. American Journal of Enology Viticulture. 16, 144-158.

Street, R.A., Sidana, J., Prinsloo, G., 2013. Cichorium intybus: Traditional Uses, Phytochemistry, Pharmacology, and Toxicology. Evid Based Complement Alternat Med., 2013, 579319. doi: 10.1155/2013/579319.

Tousch, D., Bidel, L. P. R., Cazals, G., Ferrare, K., Leroy, J., Faucanié, M., Chevassus, H., Tournier, M., Lajoix, A.-D., Azay-Milhau, J., 2014. Chemical analysis and antihyperglycemic activity of an original extract from Burdock root (Arctium lappa). J. Agric. Food Chem. 62, 7738-7745.

Tousch, D., Lajoix, A.-D., Hosy, E., Azay-Milhau, J., Ferrare, K., Jahannault, C., Cros, G., Petit, P., 2008. Chicoric acid, a new compound able to enhance insulin release and glucose uptake. Biochem. Biophys. Res. Commun. 377, 131-135.

Urgate, M., Brown, M., Hollywood, K.A., Cooper, G.J., Bishop, P.N., Dunn, W.B., 2012. Metabolomic analysis of rat serum in streptozotocin-induced diabetes and after treatment with oral triethylenetetramine (TETA). Genome Med. 4, 35.

https://doi.org/10.1186/gm334.

Villano, D., Fernandez-Pachon, M.S., Moya, M.L., Troncoso, A.M., Garcia-Parrilla, M.C., 2007. Radical scavenging ability of polyphenolic compounds towards DPPH free radical. Talanta. 71, 230-235.

Whiting, D.R., Guariguata, I., Weil, C., Shaw, J., 2011. IDF diabetes atlas: global estimates of the prevalence of diabetes for 2011 and 2030. Diabetes Res. Clin. Pract. 94, 311-321.

Zhen, Y. N., Liu, K.Y., Jia, G.Y., Li, H.P., Han, L.K.; Mucun, S.X., 2007. Effect of hot-water extract of coffee seeds on postprandial blood glucose concentration in rats. Chinese Pharmaceutical journal. 42, 32-35. 


\section{Legends of Figures and Tables:}

\section{ACCEPTED MANUSCRIPT}

Figure 1: Time course of body weight (A), food intake (B) and Glycosuria (C) in STZ diabetic rats before and during the daily intraperitoneal administrations of NCRAE (15 mg. $\mathrm{Kg}^{-1}$ ) or SCCAM (15 mg. $\mathrm{Kg}^{-1}$ ). Control animals received only IP saline solution. Four animals were used for each experimental group and the values are the means $( \pm \mathrm{SEM}) .(* *)$ $\mathrm{p}<0.01$.

Figure 2: Time course of hyperglycemia $\left(\mathrm{mg}^{\mathrm{d}} \mathrm{dL}^{-1}\right)$ in STZ diabetic rats during the daily intraperitoneal administrations of NCRAE $\left(15 \mathrm{mg} \cdot \mathrm{Kg}^{-1}\right)$ or SCCAM $\left(15 \mathrm{mg} \cdot \mathrm{Kg}^{-1}\right)$. Control animals received only IP saline solution. Four animals were used for each experimental group. Basal values were respectively $600 \pm 25 \mathrm{mg} \cdot \mathrm{dL}^{-1}, 563 \pm 32 \mathrm{mg} \cdot \mathrm{dL}^{-1}$ and $525 \pm 38$ mg.dL ${ }^{-1}$ for control, SCCAM and NCRAE treated diabetic rats. In the box (surrounded by a black border) the glycemia is presented in \% from basal values. Values are the means $( \pm \mathrm{SEM})$ by group. $(*) \mathrm{p}<0.05$ and $(* *) \mathrm{p}<0.01$.

Figure 3: Effects of daily intraperitoneal administrations of NCRAE $\left(15 \mathrm{mg} \cdot \mathrm{Kg}^{-1}\right)$ or SCCAM $\left(15 \mathrm{mg} \cdot \mathrm{Kg}^{-1}\right.$ ) on oral glucose tolerance test (OGTT) (glucose at $3 \mathrm{~g} \cdot \mathrm{Kg}^{-1}$ ) in STZ diabetic rats. OGTT were performed the $7^{\text {th }}$ day of treatments ( $\mathrm{n}=4$ rats for each experimental group) and values are the means $( \pm$ SEM). $(* *) \mathrm{p}<0.01$ and $(* * *) \mathrm{p}<0.001$.

Figure 4: Effect of a SCCAM treatment in comparison of NCRAE on the glucose-uptake in L6 muscle cell line (A) . Values are the means $( \pm \mathrm{SD})$ of three independent experiments. $\left.*^{*}\right)$ $\mathrm{p}<0.05$ and $(* *) \mathrm{p}<0.01$. Effect of a SCCAM treatment in comparison with NCRAE on the mortality induced by $\mathrm{H}_{2} \mathrm{O}_{2}$ oxidative stress applied on L6 muscle cell line (B). The duration of the treatment has been of 14 hours before the $\mathrm{H}_{2} \mathrm{O}_{2}$ application at $40 \mu \mathrm{M}$. Values are the means $( \pm \mathrm{SD})$ of three independent experiments. $(*) \mathrm{p}<0.05$. 


\section{ACCEPTED MANUSCRIPT}

Table 1: LC-MS Fingerprint with Fragmentation of NCRAE Compounds. Peaks obtained are listed in the order of elution, with their names, molecular formulas, precursor ions, and fragmentation data. TR (min): retention time in minutes. Mol. form.: molecular formula. Theo. mass: theoretical monoisotopic mass of precursor ion $[\mathrm{M}-\mathrm{H}]^{-} . \Delta \mathrm{ppm}$ : mass tolerance expressed in parts per million.

\begin{tabular}{|c|c|c|c|c|}
\hline peak & $\begin{array}{l}\text { RT } \\
(\min )^{b}\end{array}$ & $\begin{array}{l}\text { Parent ion } \\
\text { mol. form. }\end{array}$ & $\begin{array}{l}\text { Parent ion } \\
\text { theoretical } \\
\text { mass }(\mathrm{m} / \mathrm{z})^{\mathrm{d}}\end{array}$ & Fragmentation data $(\mathrm{m} / \mathrm{z})[\mathrm{M}-\mathrm{H}]^{-}$ \\
\hline $\mathrm{P} 1$ & 10.21 & $\mathrm{C}_{13} \mathrm{H}_{12} \mathrm{O}_{9}$ & 311.0403 & 311(100), 179(89), 149(100), 135(32) \\
\hline $\mathrm{P} 2$ & 12.24 & $\mathrm{C}_{13} \mathrm{H}_{12} \mathrm{O}_{9}$ & 311.0403 & $311(100), 179(40), 149(25), 135(4)$ \\
\hline P3 & 19.83 & $\mathrm{C}_{16} \mathrm{H}_{18} \mathrm{O}_{9}$ & 353.0878 & 179(75), 161(10), 135(19), 85(25) \\
\hline P4 & 21.64 & $\mathrm{C}_{16} \mathrm{H}_{18} \mathrm{O}_{9}$ & 353.0878 & 191(100), 85(12) \\
\hline P5 & 22.59 & $\mathrm{C}_{16} \mathrm{H}_{18} \mathrm{O}_{9}$ & 353.0878 & 191(34), 179(75), 173(100), 135(26) \\
\hline P6 & 23.63 & $\mathrm{C}_{22} \mathrm{H}_{19} \mathrm{O}_{13}$ & 491.0794 & $329(100), 311(10), 293(80)$ \\
\hline P7 & 35.19 & $\mathrm{C}_{22} \mathrm{H}_{18} \mathrm{O}_{12}$ & 473.0720 & $\begin{array}{l}311(100), 293(115), 219(10), 179(20), 149(31), \\
135(44)\end{array}$ \\
\hline P8 & 37.20 & $\mathrm{C}_{22} \mathrm{H}_{18} \mathrm{O}_{12}$ & 473.0720 & $\begin{array}{l}311(100), 293(88), 219(6), 179(55), 149(24), \\
135(17)\end{array}$ \\
\hline P9 & 38.10 & $\mathrm{C}_{22} \mathrm{H}_{18} \mathrm{O}_{12}$ & 473.0720 & $\begin{array}{l}311(100), 293(95), 219(5), 179(23), 149(25), \\
135(30)\end{array}$ \\
\hline $\mathrm{P} 10$ & 39.46 & $\mathrm{C}_{21} \mathrm{H}_{18} \mathrm{O}_{13}$ & 477.0669 & 301(100), 273(5), 245(10), 151(120), 179(45) \\
\hline P11 & 40.39 & $\mathrm{C}_{21} \mathrm{H}_{18} \mathrm{O}_{12}$ & 461.0720 & $285(100), 93(12)$ \\
\hline P12 & 40.86 & $\mathrm{C}_{25} \mathrm{H}_{24} \mathrm{O}_{12}$ & 515.1189 & 353(100), 335(10), 191(7), 179(19), 173(25) \\
\hline P13 & 41.80 & $\mathrm{C}_{25} \mathrm{H}_{24} \mathrm{O}_{12}$ & 515.1195 & $353(100), 191(12), 179(4), 85(10)$ \\
\hline P14 & 43.47 & $\mathrm{C}_{25} \mathrm{H}_{24} \mathrm{O}_{12}$ & 515.1195 & $353(100), 191(15), 179(7), 149(12), 135(18)$ \\
\hline P15 & 43.6 & $\mathrm{C}_{21} \mathrm{H}_{18} \mathrm{O}_{12}$ & 461.0720 & $285(100), 93(10)$ \\
\hline P16 & 44.36 & $\mathrm{C}_{25} \mathrm{H}_{24} \mathrm{O}_{12}$ & 515.1195 & $\begin{array}{l}\text { 353(100), 299(8), 203(14), 191(10), 173(25), } \\
\text { 179(10) }\end{array}$ \\
\hline P17 & 47.44 & $\mathrm{C}_{23} \mathrm{H}_{22} \mathrm{O}_{13}$ & 505.0994 & 463(60), 301(45), 151(22) \\
\hline P18 & 50.67 & $\mathrm{C}_{27} \mathrm{H}_{30} \mathrm{O}_{15}$ & 593.1511 & $447(65), 285(43)$ \\
\hline P19 & 51.02 & $\mathrm{C}_{29} \mathrm{H}_{28} \mathrm{O}_{15}$ & 615.1355 & 515(15), 453(25), 353(100), 335(5), 191(25), \\
\hline
\end{tabular}




\begin{tabular}{lllll}
\hline & & & & $127(14), 93(12), 85(10)$ \\
$\mathrm{P} 20$ & 51.88 & $\mathrm{C}_{27} \mathrm{H}_{28} \mathrm{O}_{12}$ & 543.1468 & $381(100), 161(37), 149(51), 134(5)$ \\
$\mathrm{P} 21$ & 53.51 & $\mathrm{C}_{27} \mathrm{H}_{28} \mathrm{O}_{12}$ & 543.1468 & $381(100), 161(18), 149(34), 133(4)$ \\
$\mathrm{P} 22$ & 53.98 & $\mathrm{C}_{24} \mathrm{H}_{21} \mathrm{O}_{12}$ & 339.0722 & $177(100), 133(15)$ \\
$\mathrm{P} 23$ & 53.98 & $\mathrm{C}_{24} \mathrm{H}_{21} \mathrm{O}_{12}$ & 501.1015 & $311(100), 293(93), 161(99)$ \\
\hline
\end{tabular}

Table 2 : The concentrations of each hydroxycinnamic acid were calculated by integrating Peak areas of chromatograms at $326 \mathrm{~nm}$ (maximal absorbance of CGA) and are expressed as Equivalent Absorbance of the authentic L-chicoric acid standard at $10^{-3} \mathrm{M}$.

\begin{tabular}{llll} 
Peak & $\begin{array}{l}\text { RT } \\
\text { (min) }\end{array}$ & Abs 326 & name \\
& & & \\
\hline P1 & 10.21 & 0.003 & cis-O-caffeoyltartaric acid \\
P2 & 12.24 & 8.249 & trans-O-caffeoyltartaric acid \\
P3 & 19.83 & 0.294 & trans-3-O-caffeoylquinic acid \\
P4 & 21.64 & 0.042 & trans-5-O-caffeoylquinic acid \\
P5 & 22.59 & 0.035 & trans-4-O-caffeoylquinic acid \\
P6 & 23.63 & 0.179 & caffeoyl-dihydroxy-phenyllactoyltartaric acid \\
P7 & 35.19 & 47.853 & (2S,3S)-di-O-caffeoyltartaric acid \\
P8 & 37.20 & 3.955 & (2R,3R)-di-O-caffeoyltartaric acid \\
P9 & 38.10 & 12.407 & meso-di-O-caffeoyltartaric acid \\
P10 & 39.46 & 6.630 & quercetin-3-O-glucuronide \\
P11 & 40.39 & 0.019 & kaempferol-3-O-glucuronide \\
P12 & 40.86 & 1.203 & trans-3,4-di-O-caffeoylquinic acid \\
P13 & 41.80 & 7.790 & trans-3,5-di-O-caffeoylquinic acid \\
P14 & 43.47 & 3.743 & cis-3,5-di-O-caffeoylquinic acid \\
P15 & 43.6 & 0.0001 & kaempferol-glucuronide isomer \\
P16 & 44.36 & 5.162 & trans-4,5-di-O-caffeoylquinic acid \\
P17 & 47.44 & 0.0001 & quercetin-7-O-(6"-acetyl-glucoside) \\
P18 & 50.67 & 0.0001 & kaempferol-rhamnosyl-hexoside \\
P19 & 51.02 & 0.0001 & 1,5-di-O-caffeoyl-3-O-succinoylquinic acid \\
P20 & 51.88 & 0.088 & dimethoxycinnamoyl caffeoylquinic acid isomer \\
P21 & 53.51 & 1.261 & dimethoxycinnamoyl caffeoylquinic acid isomer \\
P22 & 53.98 & 0.0001 & esculin= cichoriin \\
P23 & 55.12 & 1.087 & feruloyl-tartaric acid isomer \\
\hline
\end{tabular}




\section{ACCEPTED MANUSCRIPT}
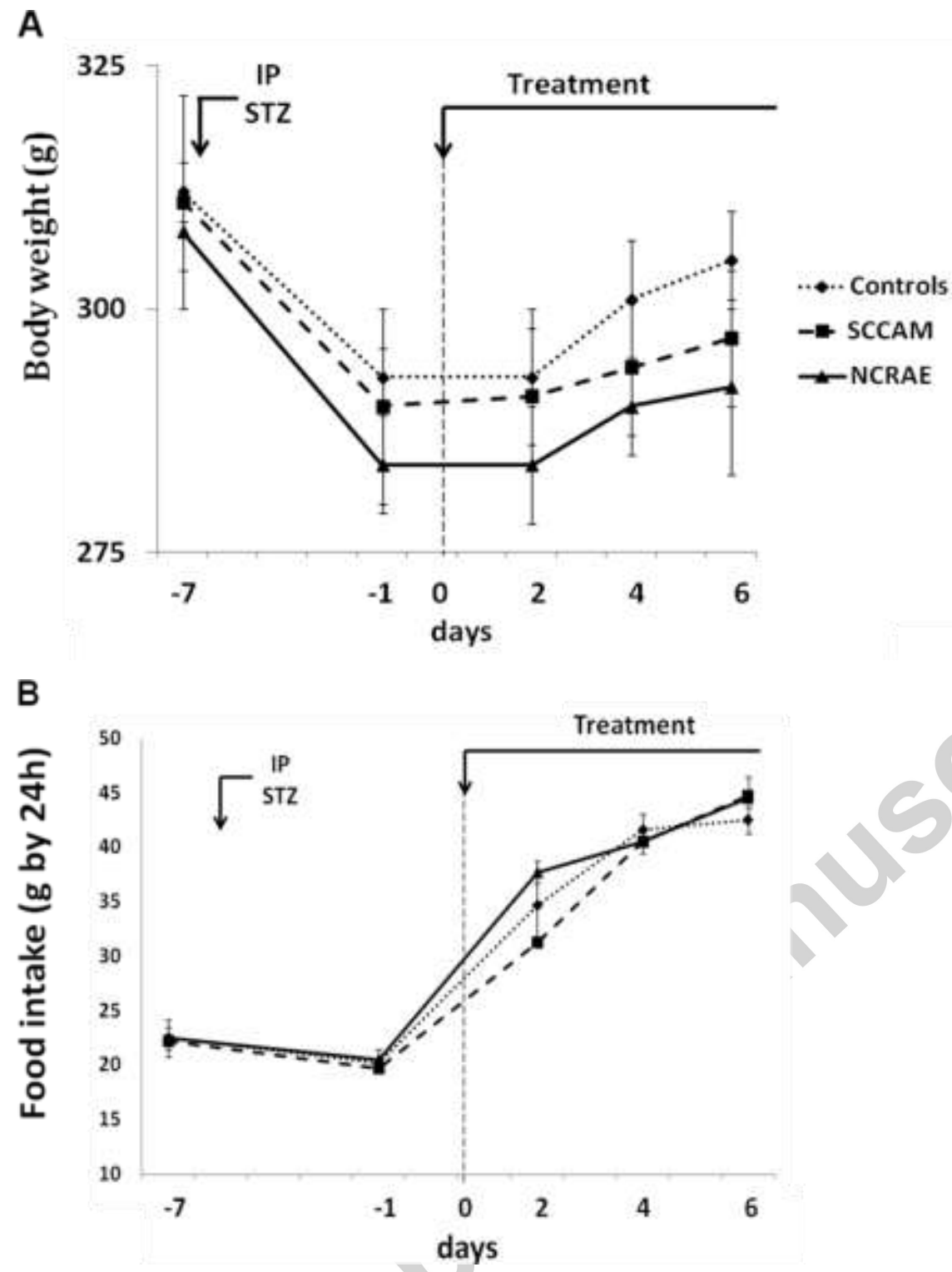


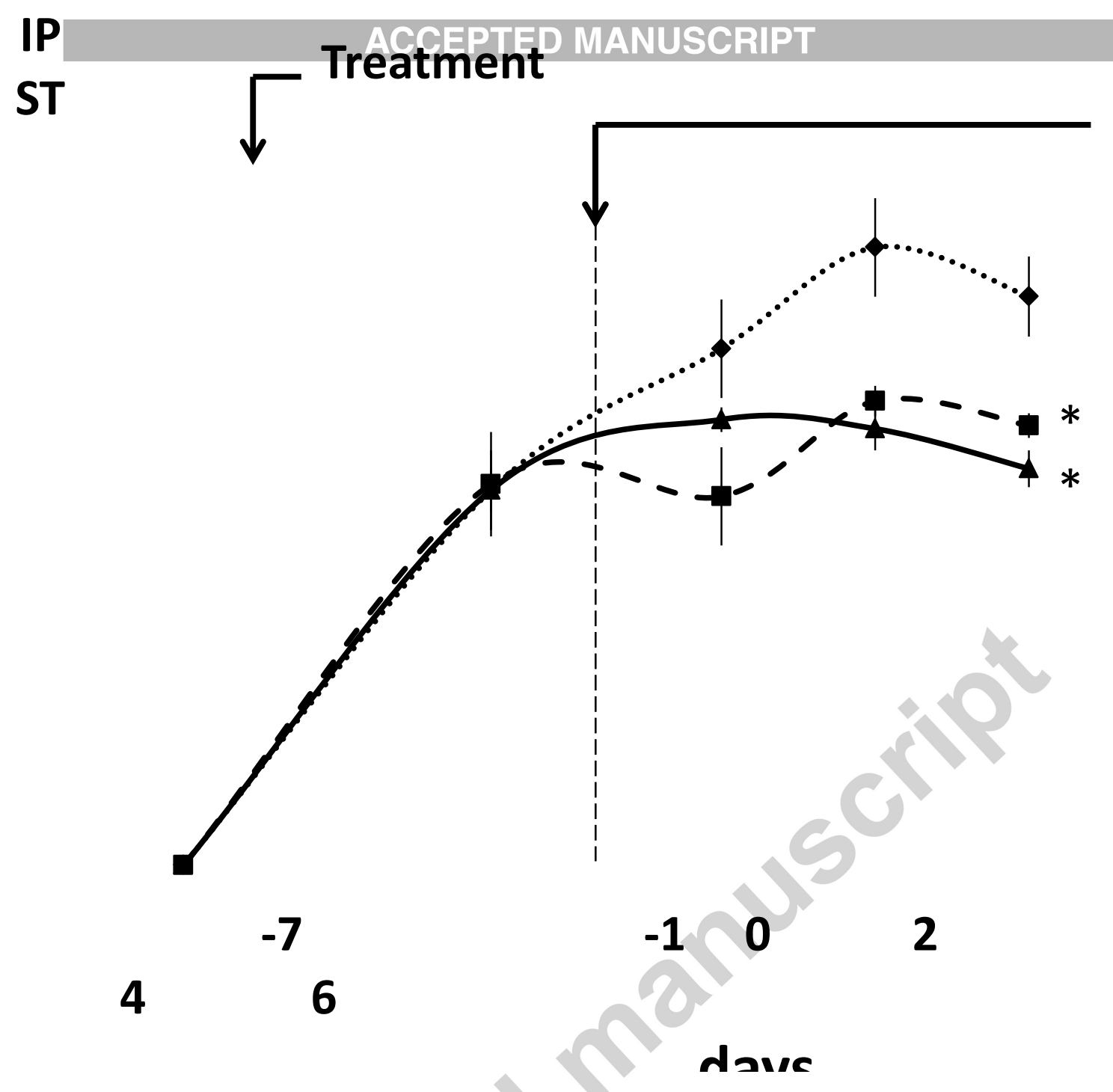

Figure 1 


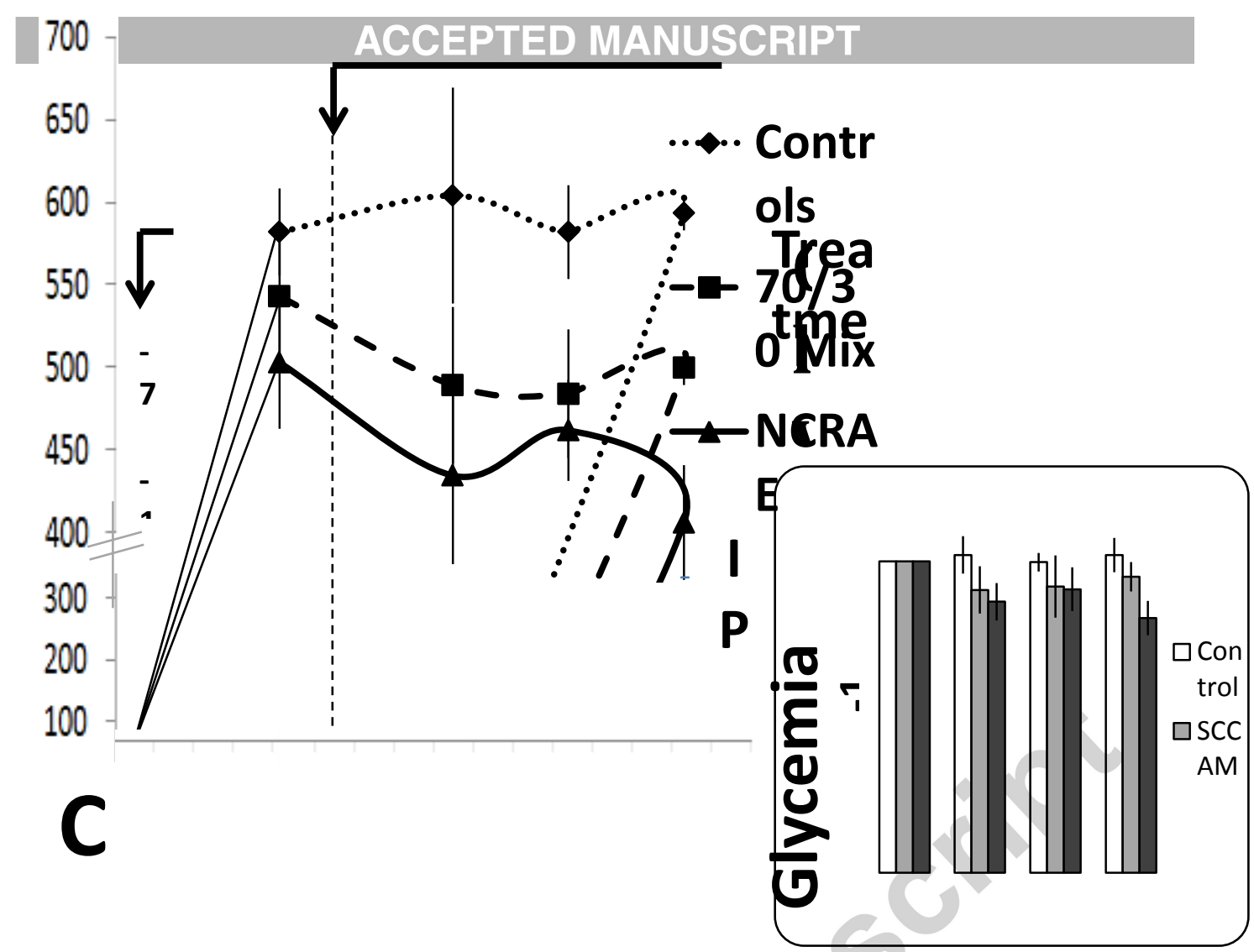

Figure 2 


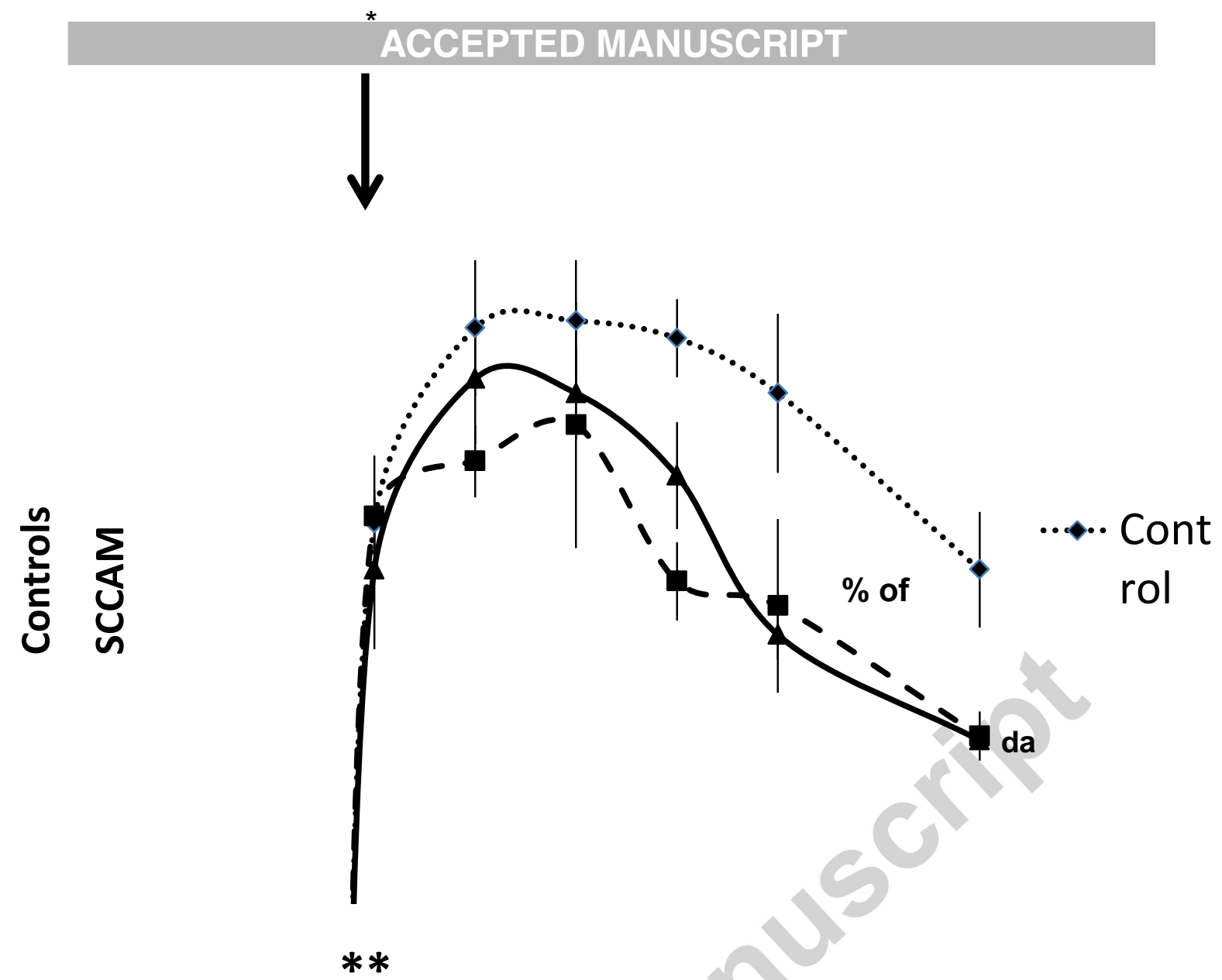

Figure 3 
A

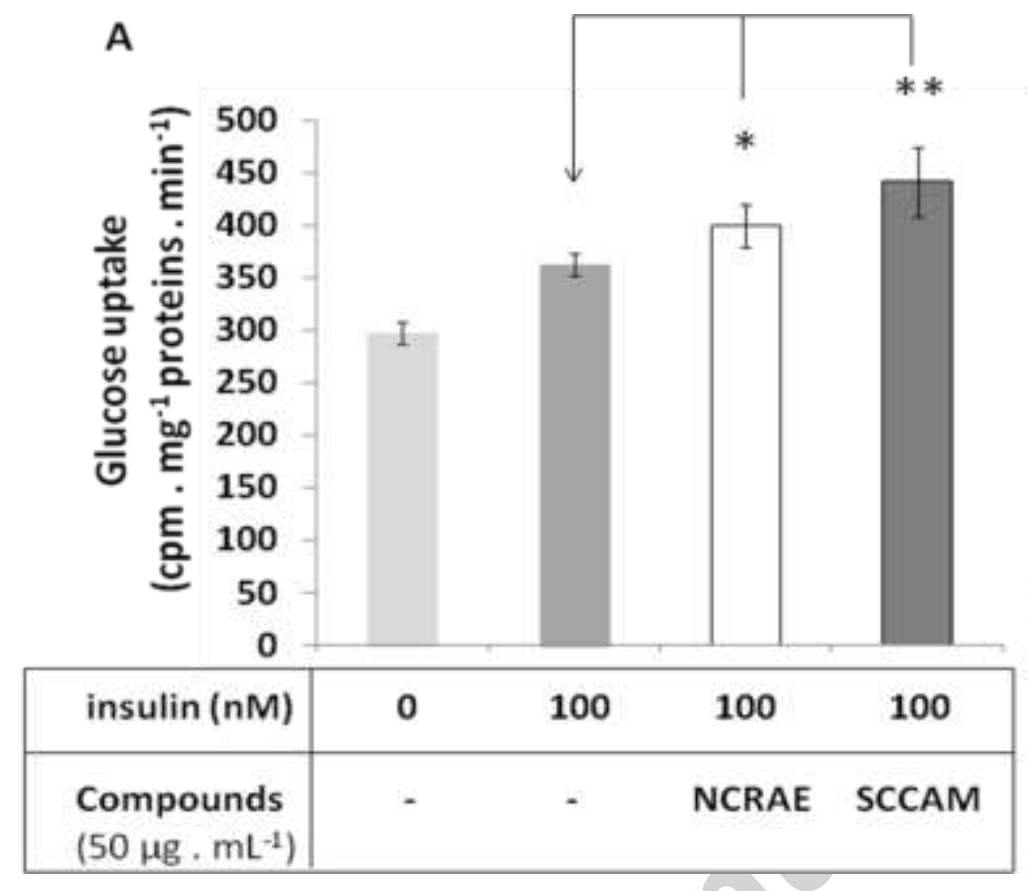

Comment citer ce document :

Ferrare, K., Bidel, L. Awwad, Poucheret, Cazals, G. Lazennec, Azay-Milhau, J., Tournier, Lajoix, Tousch, D. (Auteur de correspondance) (2018). Increase in insulin sensitivity by the association of chicoric acid and chlorogenic acid contained in a natural chicoric acid extract 
GlycemiaACCEPTED MANUSCRIPT

$-1$

$\stackrel{\circ}{\stackrel{\circ}{-1}}$

్ํ

응

:

i

0
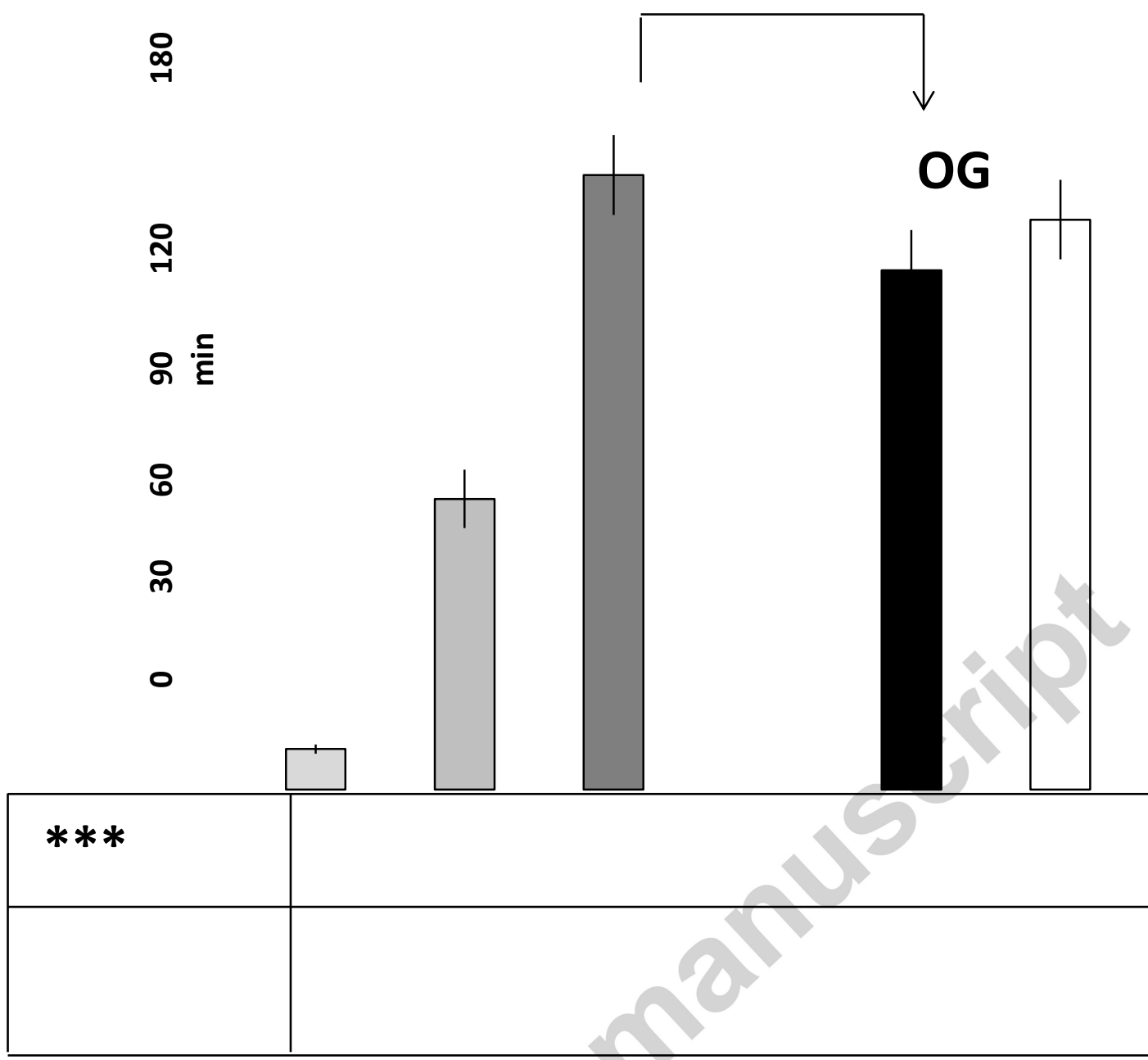

Figure 4 